\title{
Comparison and Characterisation of Regenerated Chitosan from 1-Butyl-3-methylimidazolium Chloride and Chitosan from Crab Shells
}

\author{
Saniyat Islam, Lyndon Arnold, and Rajiv Padhye \\ Centre for Advanced Materials and Performance Textiles, RMIT University, Melbourne, VIC 3056, Australia \\ Correspondence should be addressed to Saniyat Islam; saniyat.islam@rmit.edu.au
}

Received 25 July 2014; Revised 8 October 2014; Accepted 8 October 2014

Academic Editor: Paola Laurienzo

Copyright (C) 2015 Saniyat Islam et al. This is an open access article distributed under the Creative Commons Attribution License, which permits unrestricted use, distribution, and reproduction in any medium, provided the original work is properly cited.

\begin{abstract}
Chitosan is a biopolymer derived from chitin which is naturally occurring in the exoskeleton of crustaceans. This paper reports dissolution and regeneration of chitosan by directly dissolving in an ionic liquid solvent, 1-butyl-3-methylimidazolium chloride (BMIMCl). This will provide an ideal platform to solubilise these kinds of polymers to achieve the dissolution. The current study dissolved chitosan from crab shell utilising $\mathrm{BMIMCl}$ as a solvent and characterised the resultant regenerated polymer. The regenerated chitosan showed increased hydrogen bonding when characterised by Fourier transform infrared (FTIR) spectral analysis. In addition, the study also compared the characteristics of regenerated and generic chitosan. The regenerated chitosan was also evaluated for antimicrobial properties and showed to possess antibacterial features similar to the commercial grade. This method can be utilised in future for blending of polymers with chitosan in a dissolved phase.
\end{abstract}

\section{Introduction}

Chitosan (CHT) is a linear polysaccharide composed of randomly distributed $\beta$-(1-4)-linked D-glucosamine (deacetylated unit) and $\mathrm{N}$-acetyl-D-glucosamine (acetylated unit) [19]. Chitosan is formed commercially by deacetylation of chitin, which is the compositional element in the exoskeleton of crustaceans such as crabs, shrimps, and lobsters. Preparation of chitosan from chitin is given in Figure 1.

CHT has three reactive groups and they are primary (C-6) and secondary (C-3) hydroxyl $(-\mathrm{OH})$ groups and the amino$\mathrm{NH} 2$ (C-2) group in each repeat of the deacetylated unit of chitin. Thus it is polycationic in nature. The antimicrobial activity of CHT and its derivatives has been well proven in past studies but the mechanism of the antimicrobial action is yet to be discovered. The most acceptable interpretation is that the anionic cell surface of the microbes interacts with the cationic CHT, causing extensive cell surface alterations and damage. This leads to inhibition of the metabolism of the cell and results in its death [10]. So far it is considered that $\mathrm{CHT}$ acts as a biocide for some microbes and as a biostatic agent for others [11]. Other than its antimicrobial activity, CHT has been extensively studied for other applications such as photography, cosmetics, artificial skin, dressings and wound healing, food and nutrition, wastewater treatment, and dyeing and printing [12]. CHT also has been investigated for its capability of forming continuous films [13-16].

Ionic liquids (ILs) can be derived from a wide variety of complex compounds such as salts of imidazolium, ammonium, pyridinium, isoquinolinium, sulfonium, phosphonium, and pyrrolidinium [17]. Ionic liquids based on monosubstituted to pentasubstituted imidazolium ions are favourable species for investigation in textiles because of their air and water stability, their wide range of liquidity, the fact that they remain liquid at room temperature, and their relatively favourable viscosity and density characteristics $[18,19]$. This paper reviewed the developments and applications of one significant IL with application for textiles and polymers, specifically, 1-butyl-3-methylimidazolium chloride (BMIMCl) which has the chemical structure shown in Figure 2 [6]. 


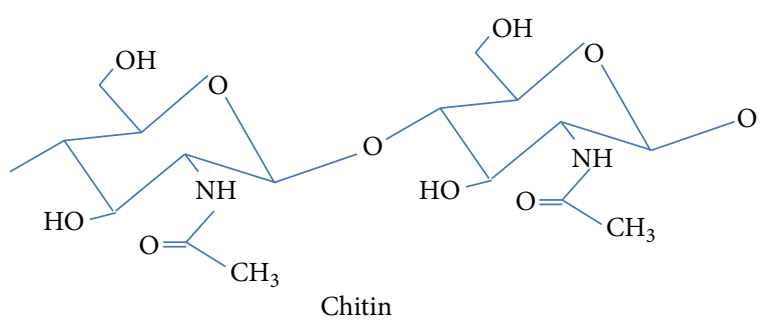

( $\beta(1,4)$-2-acetamido-2-deoxy-D-glucopyranose)

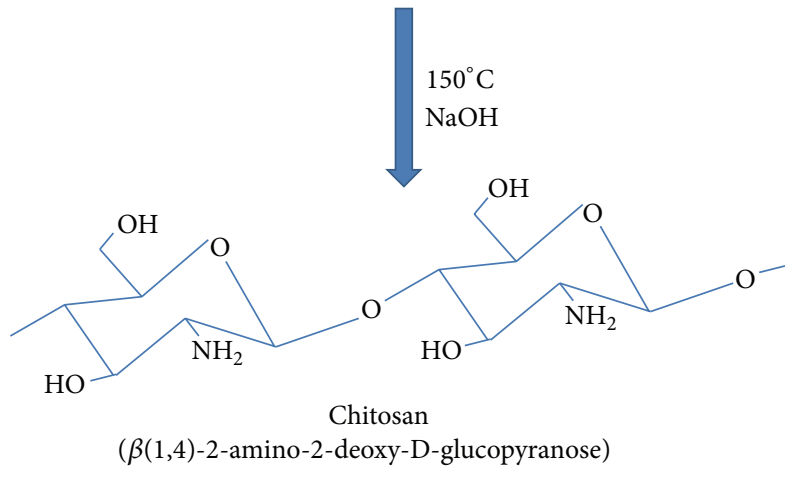

FIGURE 1: Deacetylation of chitin to obtain CHT [1].

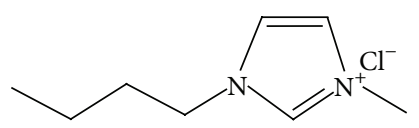

FIgURE 2: Chemical structure of BMIMCl.

\section{Materials and Methods}

Practical grade CHT from crab shells (Brookfield viscosity $200 \mathrm{cP}, 1 \%$ in $1 \%$ acetic acid, degree of deacetylation $>85 \%$, and molecular weight 190,000->375,000, which is based on the viscosity of $200-2000 \mathrm{mPa} \cdot \mathrm{s}$ ) was sourced from SigmaAldrich Pty Ltd., Australia, and used as received for the experiments. BMIMCl was also sourced from Sigma-Aldrich, Australia, and used without any modification.

2.1. Regeneration of CHT from BMIMCL. To dissolve the $\mathrm{CHT}, 1 \mathrm{~g}$ of $\mathrm{CHT}$ was mixed with $20 \mathrm{~mL}$ of BMIMCl, heated, and stirred at $100^{\circ} \mathrm{C} \sim 130^{\circ} \mathrm{C}$ to obtain a $5 \mathrm{wt} \%$ completely homogeneous CHT solution. The dissolved CHT could be regenerated in water as $\mathrm{BMIMCl}$ is completely miscible with water in any ratio. This can be done by pouring the viscous solution into deionised water and coagulated several times. Regenerated CHT was obtained by casting the viscous solution between two circular microscopic slides and then soaked in water bath to allow BMIMCl diffusion from the films. During this process, water was changed several times to visually confirm that the BMIMCl had been removed completely from the sample; that is, no diffusion of $\mathrm{BMIMCl}$ could be observed. This was further confirmed by FTIR spectroscopy and discussed in the results section. After washing with deionised water several times the regenerated CHT films were dried in a vacuum oven to get flat blend films.
2.2. FTIR Spectroscopy. The FTIR spectra were collected by a spectrometer (PerkinElmer Spectrum-400) to determine the functional groups of the fibres/fabrics. The number of scans per sample was 8 and the FTIR spectra were collected in the wave number region of $4000-650 \mathrm{~cm}^{-1}$. The spectra indicated the absorbance/transmittance of a material as a function of wave number.

2.3. Antibacterial Testing. A modified AATCC TM 1002004 (clause 10.2) test method was followed to assess the antibacterial properties of samples. Escherichia coli (E. coli) strain-ATCC 11229, a gram-negative bacterium, was used as the test organism. Bacterial inoculums were prepared to obtain a suspension in an exponential growth of $10^{8}$ colony forming units (CFU) $\mathrm{mL}^{-1}$ in $5 \mathrm{~mL}$ of modified tryptone-soy nutrient broth. Fabrics dyed in the absence of CHT were used as negative control samples. Antibacterial tests were conducted on each sample individually as outlined by Zhang et al. [20]. In brief, $1 \mathrm{~mL}$ of inoculum was added to a $0.1 \mathrm{gm}$ of CHT in a conical flask. $100 \mathrm{~mL}$ of distilled water was added to the flask and this was shaken vigorously for 1 minute. From this solution, a series of dilutions were prepared as $10^{0}, 10^{1}$, $10^{2}$, and $10^{3}$ times with sterile distilled water. The dilutions were then plated in triplicate and incubated for 18 hours at $37^{\circ} \mathrm{C}$. After incubation, the control plates exhibiting 30-300 colony forming units were taken as reference. Test plates of a similar dilution were compared. The percentage reduction of bacteria was calculated by the following equation [21]:

$$
\text { Reduction in CFU\% }=\frac{(X-Y)}{X} \times 100 \% \text {, }
$$

where $X$ is the average number of bacterial colonies in the control and $Y$ is the average number of bacterial colonies in the presence of CHT.

\section{Results and Discussion}

Regenerated CHT from BMIMCl was characterised for its morphological changes as dissolution and regeneration occur. The appearance can be distinguished as defragmented scaly structure. It is noticeable that although the film visibly seems uniform, the scaly structure is apparent throughout the film region inspected. Figure 3 shows the morphological structure of a typical CHT film prepared from BMIMCl at different locations within the film.

FTIR studies of CHT from crab shells (sourced from Sigma-Aldrich) and CHT of the same regenerated from $\mathrm{BMIMCl}$ solution were characterised for any chemical and structural derivatisation of CHT in both forms.

The normalised spectrum obtained from FTIR spectroscopy of BMIMCl is shown in Figure 4 [6]. The functional groups present and their respective wave numbers $\left(\mathrm{cm}^{-1}\right)$ and intensities (\%T) confirm the chemical structures given in Figure 4. The peak stretching at wave number $3385\left(\mathrm{~cm}^{-1}\right)$ corresponds to $\mathrm{N}-\mathrm{H}\left(2^{\circ}\right.$ amines $)$ bonding. The wave numbers from $3138\left(\mathrm{~cm}^{-1}\right)$ to $2872\left(\mathrm{~cm}^{-1}\right)$ refer to $\mathrm{O}-\mathrm{H}$ stretching. The bending at $1643\left(\mathrm{~cm}^{-1}\right)$ is indicative of $\mathrm{C}=\mathrm{N}$ and $\mathrm{C}=\mathrm{C}$ 

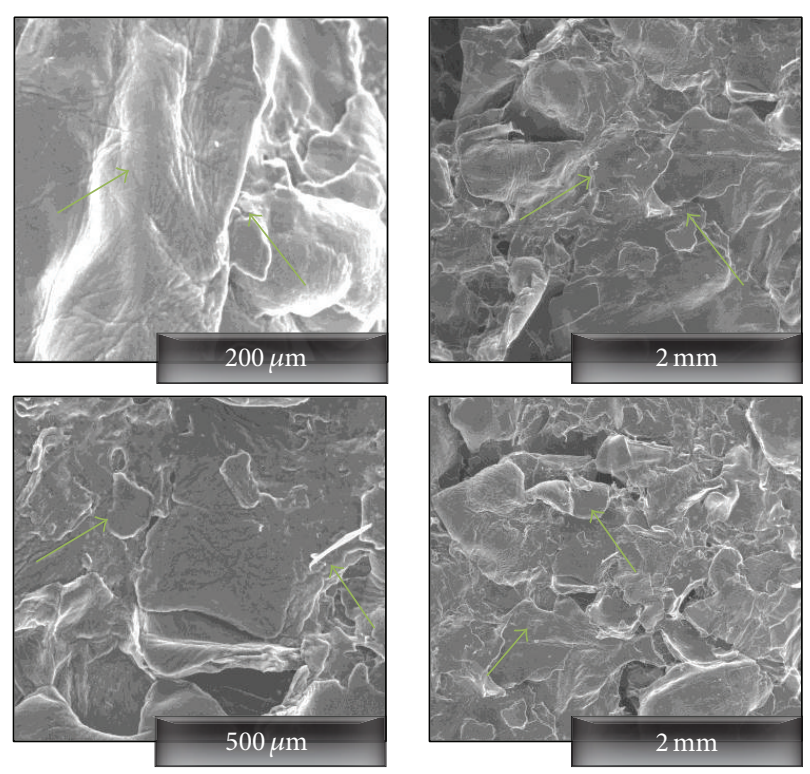

FIGURE 3: Appearance of a scaly structure at various locations of the $\mathrm{CHT}$ film regenerated from $\mathrm{BMIMCl}$ solution.

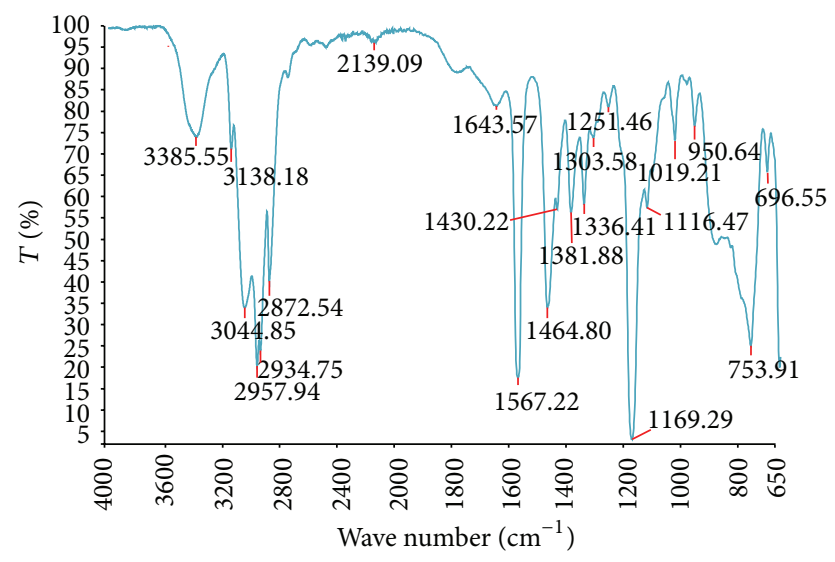

FIGURE 4: FTIR spectrum of BMIMCl.

bonding and peak ranging between $696\left(\mathrm{~cm}^{-1}\right)$ and 1567 $\left(\mathrm{cm}^{-1}\right)$ corresponds to stretching $\mathrm{C}-\mathrm{C}, \mathrm{C}-\mathrm{O}$, or $\mathrm{C}-\mathrm{N}$ bonds.

FTIR spectra of CHT from crab shells and CHT regenerated from BMIMCl are shown in Figure 5.

Both spectra show similar patterns; however, the regenerated CHT produced sharper peaks at $3359 \mathrm{~cm}^{-1}$ and in the $1030-1155 \mathrm{~cm}^{-1}$ regions. The transmittance peak in this area indicates stretching of the $\mathrm{O}-\mathrm{H}$ and $\mathrm{N}-\mathrm{H}$ bonds at $3359 \mathrm{~cm}^{-1}$ and C-O bonds at $1030-1155 \mathrm{~cm}^{-1}$, respectively. In addition, absorption peaks in the $2880 \mathrm{~cm}^{-1}$ region, around $1550-1590 \mathrm{~cm}^{-1}$ and $1400 \mathrm{~cm}^{-1}$, correspond to C-H stretching, amine groups- $\left(\mathrm{NH}_{2}\right)$, and carboxyl groups $\left(-\mathrm{COO}^{-}\right)$, respectively [22]. A band at $3359 \mathrm{~cm}^{-1}$ corresponds to the combined peaks of the $\mathrm{NH}_{2}$ and $\mathrm{O}-\mathrm{H}$ group stretching vibration in CHT. The band at $1641 \mathrm{~cm}^{-1}$ is attributed to the $\mathrm{CO}-\mathrm{NH}_{2}$ group. The $1598 \mathrm{~cm}^{-1}$ transmittance peak of the $-\left(\mathrm{NH}_{2}\right)$ bending vibration is sharper than the peak at

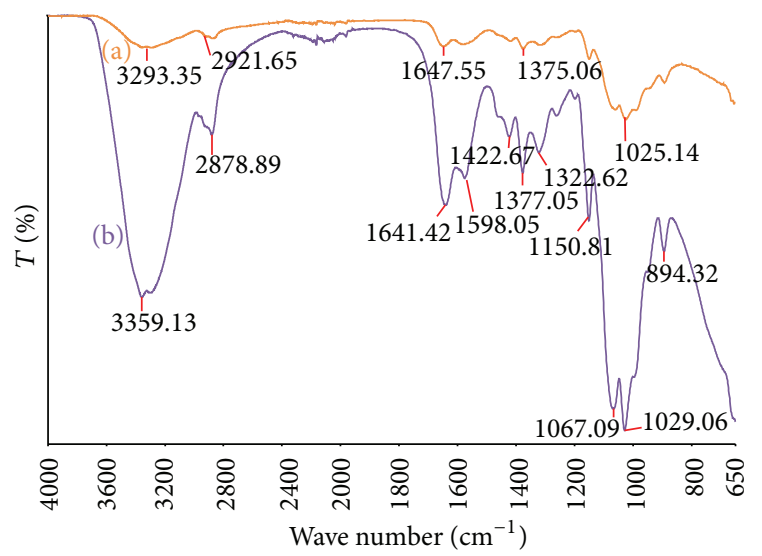

FIgURE 5: FTIR spectra of (a) CHT from crab shell and (b) CHT regenerated from $\mathrm{BMIMCl}$.

$1641 \mathrm{~cm}^{-1}$, which shows the high degree of deacetylation of the CHT. A shift from 3293 to $3359 \mathrm{~cm}^{-1}$ is shown and the peak is sharper in the regenerated CHT, which indicates that the hydrogen bonding is enhanced [23].

The intensities of the $\left(\mathrm{CO}-\mathrm{NH}_{2}\right)$ band at $1641 \mathrm{~cm}^{-1}$ and the $\left(\mathrm{NH}_{2}\right)$ band at $1598 \mathrm{~cm}^{-1}$, which can be observed clearly in pure CHT, increase dramatically, and two new sorption bands at $1422 \mathrm{~cm}^{-1}$ and $1322 \mathrm{~cm}^{-1}$ appear, which show asymmetrical C-H bending of the $\mathrm{CH}_{2}$ group. Thus it is postulated that the halide $\left(\mathrm{Cl}^{-}\right)$of $\mathrm{BMIMCl}$ interacts with the ammonium groups of CHT, which serves to enhance both the inter- and intramolecular interaction in regenerated CHT [24]. To summarise, $3429 \mathrm{~cm}^{-1}$ (O-H stretching overlapping the $\mathrm{N}-\mathrm{H}$ stretching), 2921 and $2878 \mathrm{~cm}^{-1}$ (C$\mathrm{H}$ stretching), $1641 \mathrm{~cm}^{-1}$ (amide II band, C-O stretching of the acetyl group), $1598 \mathrm{~cm}^{-1}$ (amide II band, $\mathrm{N}-\mathrm{H}$ stretching), $1485-1380 \mathrm{~cm}^{-1}$ (asymmetrical $\mathrm{C}-\mathrm{H}$ bending of the $\mathrm{CH}_{2}$ group), and $1029 \mathrm{~cm}^{-1}$ (O-bridge stretching) of the glucosamine residue [25] of CHT can be characterised using FTIR spectroscopy. This also indicates that no derivatisation occurred during the dissolution and regeneration stages. In addition, the fingerprint bands of $\mathrm{BMIMCl}$ are absent in the regenerated $\mathrm{CHT}$ when compared to Figure 4 which confirms complete removal of $\mathrm{BMIMCl}$ in the washing process. The assignments of the bands are listed in Table 1 .

3.1. Calculation of Degree of Deacetylation from FTIR Spectra. The degree of deacetylation (DD) is one of the most important chemical parameters capable of influencing the performance of CHT in many of its applications [25-28], one of them being antimicrobial efficacy. Several analytical techniques were developed for DD determination using IR spectroscopy. Quite a few absorption band ratios, such as A1560/A2875, A1655/A2875, A1655/A3450, A1320/A3450, A1655/A1070, A1655/A1030, A1560/A1160, A1560/A897, and A1320/A1420, have been suggested by several researchers [29] to determine DD by FTIR spectroscopy. Since the CHT used 
TABLE 1: FTIR bands of CHT and regenerated CHT with assignments.

\begin{tabular}{|c|c|}
\hline Wave number $\left(\mathrm{cm}^{-1}\right)$ & Vibrational assignments \\
\hline 3359 & $\mathrm{O}-\mathrm{H}$ and $\mathrm{N}-\mathrm{H}$ stretch \\
\hline 2921 and 2878 & $\mathrm{C}-\mathrm{H}$ stretch \\
\hline 1641 & Amide II and C-O stretch of acetyl group \\
\hline 1598 & $\begin{array}{l}\mathrm{N}-\mathrm{H} \text { stretching from amide I and amide } \\
\text { II }\end{array}$ \\
\hline $1485-1380$ & $\begin{array}{l}\text { Asymmetrical C-H bending of the } \mathrm{CH}_{2} \\
\text { group }\end{array}$ \\
\hline 1067 & $\begin{array}{l}\text { Asymmetric stretch } \mathrm{C}-\mathrm{O}-\mathrm{C} \text { and } \mathrm{C}-\mathrm{N} \\
\text { stretch }\end{array}$ \\
\hline 1029 & $\begin{array}{l}\text { O-bridge stretching of the glucosamine } \\
\text { residue }\end{array}$ \\
\hline
\end{tabular}

TABLE 2: Reduction in CFU\% according to (1).

\begin{tabular}{lcc}
\hline Sample & Plate count & Reduction in CFU\% \\
\hline Control & Uncountable & 0 \\
CHT from crab shell & 0 & $100 \%$ \\
Regenerated CHT & 0 & $100 \%$ \\
\hline
\end{tabular}

for the current study has DD of $>85 \%$ (supplier's information), two calculation methods were used to determine DD of the CHT and regenerated CHT [29]:

$$
\frac{A_{1560}}{A_{2875}}=0.0125 \times \mathrm{DD}+0.2 \quad\left(R^{2}=0.99\right) .
$$

See [30]:

$$
\mathrm{DD}=118.883-\left(40.1647 \times \frac{A_{1655}}{A_{3450}}\right) .
$$

See [31].

Equation (2) produces a calculated DD value of $70 \%$ and (3) suggests a calculated DD of $68 \%$ and both the values are lower than the specification provided by the manufacturer. However, for the regenerated CHT samples, the calculated values of DD are $89 \%$ and $84 \%$ which closely matches the supplier's specification. This increase can be attributed to higher hydrogen bonding caused by dissolution and regeneration phenomenon.

3.2. Temperature-Dependent Dissolution Phenomena. The dissolution phenomenon of CHT was investigated and the total amount dissolved in a particular amount of BMIMCl was calculated as a function of time elapsed to dissolve the sample. A graph was plotted (as shown in Figure 6) to show the dissolution.

Recent studies [32,33] compared dissolution polymers in a variety of ionic liquids. However, the time it takes to reach the maximum yield was reported differently in several studies [34-36]. As can be seen from Figure 5, the dissolution temperature for $\mathrm{CHT}$ started from $90^{\circ} \mathrm{C}$ and the

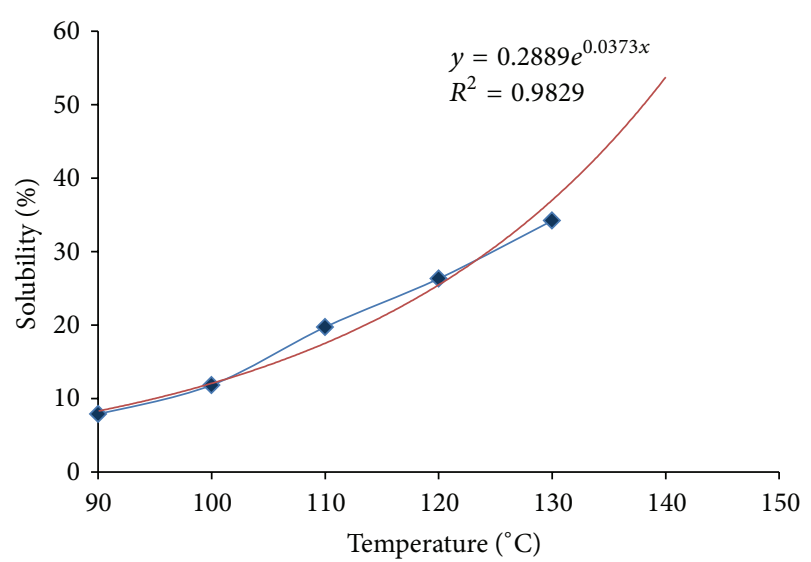

FIgUrE 6: Temperature-dependent dissolution of CHT (blue) in BMIMCl.

maximum yield was reached at $130^{\circ} \mathrm{C}$. In addition, the time of dissolution was observed to be much less (4 hours) than in previous studies. This anomaly can be explained by the elevated temperature as well as the fineness and form of CHT samples used (powder or larger scales). The maximum yield was observed to be approximately $5 \%$ on the weight of $\mathrm{BMIMCl}$ used, which is in good agreement with previous studies $[35,36]$. An equation for the dissolution of $\mathrm{CHT}$ in $\mathrm{BMIMCl}$ is derived by plotting an exponential curve fit. The generalised equation for exponential scale is $y=e^{m x}$ :

For CHT dissolution, $y=0.2889 e^{0.0373 x} \quad\left(R^{2}=0.9829\right)$,

where $m$ is the dissolution rate of the polymer.

3.3. Antibacterial Evaluation. Figure 7 shows the antibacterial effect of the two CHT samples against the control. As there was no growth observed the antibacterial activity was excellent for both sources of CHT samples.

The outcome of the antibacterial testing conducted is summarised in Table 2. As the samples were repeated in triplicate the results are averaged for tabulation.

\section{Conclusion}

A comparative study of $\mathrm{CHT}$ from crab shells and regenerated of the same from BMIMCl showed that CHT can be dissolved and regenerated in BMIMCl without any decrease in the functional attributes such as antibacterial behaviour. The commercial grade of CHT used in this study can usually be dissolved by weak acids; however, these media might not be suitable for other polymers when solution blending is required. BMIMCl provides an ideal medium for solution blending of different natural polymers with $\mathrm{CHT}$ which has been shown in this study. 


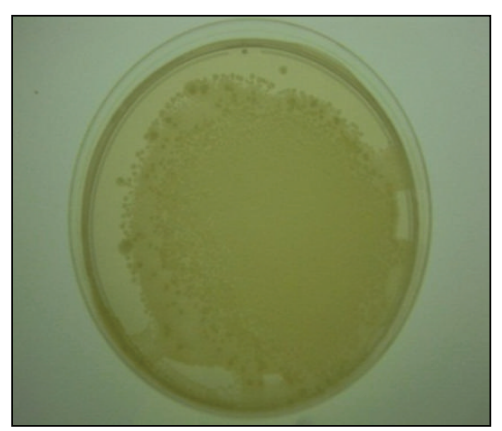

(a)

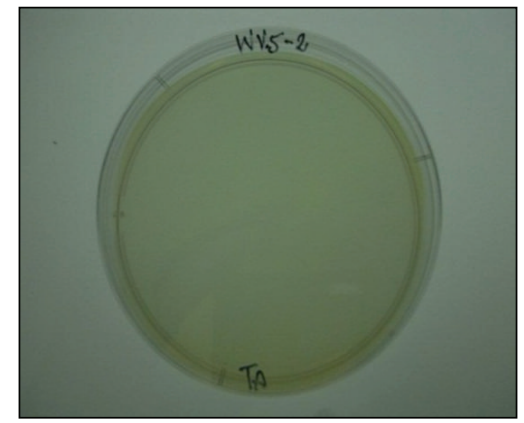

(b)

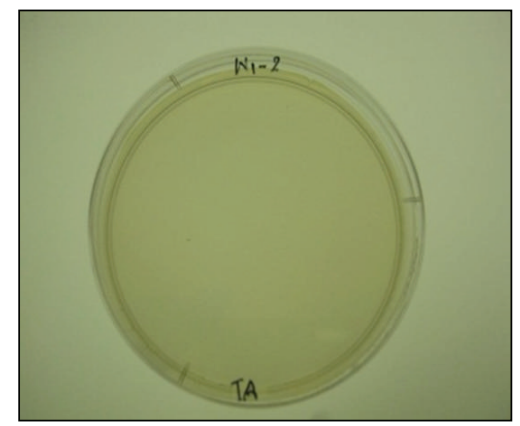

(c)

Figure 7: (a) Control showing complete growth of bacteria and (b) CHT from crab shell showing no growth and (c) CHT regenerated from BMIMCL showing no growth.

\section{Conflict of Interests}

The authors declare that there is no conflict of interests regarding the publication of this paper.

\section{Acknowledgment}

The authors would like to thank the Australian Wool Education Trust (AWET) for financially supporting this project.

\section{References}

[1] Y. Gao and R. Cranston, "Recent advances in antimicrobial treatments of textiles," Textile Research Journal, vol. 78, no. 1, pp. 60-72, 2008.

[2] M. Dash, F. Chiellini, R. M. Ottenbrite, and E. Chiellini, "Chitosan-a versatile semi-synthetic polymer in biomedical applications," Progress in Polymer Science, vol. 36, no. 8, pp. 9811014, 2011.

[3] W. Paul and C. P. Sharma, "Chitosan and alginate wound dressings: a short review," Trends in Biomaterials and Artificial Organs, vol. 18, no. 1, pp. 18-23, 2004.

[4] S. Islam, L. Arnold, and R. Padhye, "Wound dressing utilising nonwoven wool matrix," Advanced Materials Research, vol. 535, pp. 1534-1541, 2012.

[5] S. Islam, L. Arnold, and R. Padhye, "Application of chitosan on wool-viscose nonwoven for wound dressing," Journal of Biobased Materials and Bioenergy, vol. 7, no. 4, pp. 439-443, 2013.

[6] S. Islam, L. Arnold, and R. Padhye, "Ionic liquids-rcomposing the past and writing the future," Smartex Research Journal, vol. 1, no. 1, pp. 72-79, 2012.

[7] S. Islam, A. Cheung, L. Wang, L. Arnold, and R. Padhye, "Application of crab shell chitosan on nonwoven wool," Advanced Materials Research, vol. 472, pp. 82-88, 2012.

[8] S. Islam, A. Jadhav, J. Fang et al., "Surface deposition of chitosan on wool substrate by electrospraying," Advanced Materials Research, vol. 331, pp. 165-170, 2011.

[9] S. Islam, O. Troynikov, and R. Padhye, "New automotive fabrics with anti-odour and antimicrobial properties," in Sustainable Automotive Technologies 2012, A. Subic, J. Wellnitz, M. Leary, and L. Koopmans, Eds., pp. 81-89, Springer, Berlin, Germany, 2012.

[10] S. H. Lim, Synthesis of a fiber-reactive chitosan derivative and its application to cotton fabric as an antimicrobial finish and a dyeing-improving agent [Ph.D. thesis], 2003.

[11] S. Ratnapandian, S. Islam, L. Wang, S. M. Fergusson, and R. Padhye, "Colouration of cotton by combining natural colourants and bio-polysaccharide," Journal of the Textile Institute, vol. 104, no. 12, pp. 1269-1276, 2013.

[12] M. N. V. Ravi Kumar, "Chitin and chitosan fibres: a review," Bulletin of Materials Science, vol. 22, no. 5, pp. 905-915, 1999.

[13] A. D. Sezer, F. Hatipoğlu, E. Cevher, Z. Oğurtan, A. L. Baş, and J. Akbuğa, "Chitosan film containing fucoidan as a wound dressing for dermal burn healing: preparation and in vitro/in vivo evaluation," AAPS PharmSciTech, vol. 8, no. 2, article 39, 2007.

[14] S. Islam, O. Troynikov, and R. Padhye, "New automotive fabrics with anti-odour and antimicrobial properties," in Sustainable Automotive Technologies 2012, pp. 81-89, Springer, New York, NY, USA, 2012.

[15] C. Caner, P. J. Vergano, and J. L. Wiles, "Chitosan film mechanical and permeation properties as affected by acid, plasticizer, and storage," Journal of Food Science, vol. 63, no. 6, pp. 10491053, 1998.

[16] J. Nunthanid, S. Puttipipatkhachorn, K. Yamamoto, and G. E. Peck, "Physical properties and molecular behavior of chitosan films," Drug Development and Industrial Pharmacy, vol. 27, no. 2, pp. 143-157, 2001.

[17] S. Zhang, N. Sun, X. He, X. Lu, and X. Zhang, "Physical properties of ionic liquids: database and evaluation," Journal of Physical and Chemical Reference Data, vol. 35, no. 4, pp. 14751517, 2006.

[18] J. S. Wilkes and M. J. Zaworotko, "Air and water stable 1-ethyl-3methylimidazolium based ionic liquids," Journal of the Chemical Society, Chemical Communications, no. 13, pp. 965-967, 1992.

[19] J. Fuller, R. T. Carlin, H. C. De Long, and D. Haworth, "Structure of 1-ethyl-3-methylimidazolium hexafluorophosphate: model 
for room temperature molten salts," Journal of the Chemical Society, Chemical Communications, no. 3, pp. 299-300, 1994.

[20] F. Zhang, D. Zhang, Y. Y. Chen, and H. Lin, "The antimicrobial activity of the cotton fabric grafted with an amino-terminated hyperbranched polymer," Cellulose, vol. 16, no. 2, pp. 281-288, 2009.

[21] F. Zhang, D. S. Zhang, Y. Y. Chen, and H. Lin, "The antimicrobial activity of the cotton fabric grafted with an aminoterminated hyperbranched polymer," Cellulose, vol. 16, no. 2, pp. 281-288, 2009.

[22] Y. Pranoto, S. K. Rakshit, and V. M. Salokhe, "Enhancing antimicrobial activity of chitosan films by incorporating garlic oil, potassium sorbate and nisin," LWT-Food Science and Technology, vol. 38, no. 8, pp. 859-865, 2005.

[23] L. Qi, Z. Xu, X. Jiang, C. Hu, and X. Zou, "Preparation and antibacterial activity of chitosan nanoparticles," Carbohydrate Research, vol. 339, no. 16, pp. 2693-2700, 2004.

[24] J. Z. Knaul, S. M. Hudson, and K. A. M. Creber, "Improved mechanical properties of chitosan fibers," Journal of Applied Polymer Science, vol. 72, no. 13, pp. 1721-1732, 1999.

[25] J. Kumirska, M. Czerwicka, Z. Kaczyński et al., "Application of spectroscopic methods for structural analysis of chitin and chitosan," Marine Drugs, vol. 8, no. 5, pp. 1567-1636, 2010.

[26] S.-H. Lim and S. M. Hudson, "Review of chitosan and its derivatives as antimicrobial agents and their uses as textile chemicals," Journal of Macromolecular Science Part C: Polymer Reviews, vol. 43, no. 2, pp. 223-269, 2003.

[27] S.-H. Lim and S. M. Hudson, "Application of a fiber-reactive chitosan derivative to cotton fabric as an antimicrobial textile finish," Carbohydrate Polymers, vol. 56, no. 2, pp. 227-234, 2004.

[28] S.-H. Lim and S. M. Hudson, "Synthesis and antimicrobial activity of a water-soluble chitosan derivative with a fiberreactive group," Carbohydrate Research, vol. 339, no. 2, pp. 313319, 2004.

[29] M. R. Kasaai, "A review of several reported procedures to determine the degree of $\mathrm{N}$-acetylation for chitin and chitosan using infrared spectroscopy," Carbohydrate Polymers, vol. 71, no. 4, pp. 497-508, 2008.

[30] Y. Dong, C. Xu, J. Wang, Y. Wu, M. Wang, and Y. Ruan, "Influence of degree of deacetylation on critical concentration of chitosan/dichloroacetic acid liquid-crystalline solution," Journal of Applied Polymer Science, vol. 83, no. 6, pp. 1204-1208, 2002.

[31] S. Rout, Physicochemical, functional, and spectroscopic analysis of crawfish chitin and chitosan as affected by process modification [Dissertation, thesis], 2001.

[32] W. Xiao, Q. Chen, Y. Wu, T. Wu, and L. Dai, "Dissolution and blending of chitosan using 1,3-dimethylimidazolium chloride and 1-H-3-methylimidazolium chloride binary ionic liquid solvent," Carbohydrate Polymers, vol. 83, no. 1, pp. 233-238, 2011.

[33] C. Stefanescu, W. H. Daly, and I. I. Negulescu, "Biocomposite films prepared from ionic liquid solutions of chitosan and cellulose," Carbohydrate Polymers, vol. 87, no. 1, pp. 435-443, 2012.

[34] N. Hameed and Q. Guo, "Blend films of natural wool and cellulose prepared from an ionic liquid," Cellulose, vol. 17, no. 4, pp. 803-813, 2010

[35] H. Xie, S. Li, and S. Zhang, "Ionic liquids as novel solvents for the dissolution and blending of wool keratin fibers," Green Chemistry, vol. 7, no. 8, pp. 606-608, 2005.
[36] H. Xie, S. Zhang, and S. Li, "Chitin and chitosan dissolved in ionic liquids as reversible sorbents of $\mathrm{CO}_{2}$," Green Chemistry, vol. 8, no. 7, pp. 630-633, 2006. 

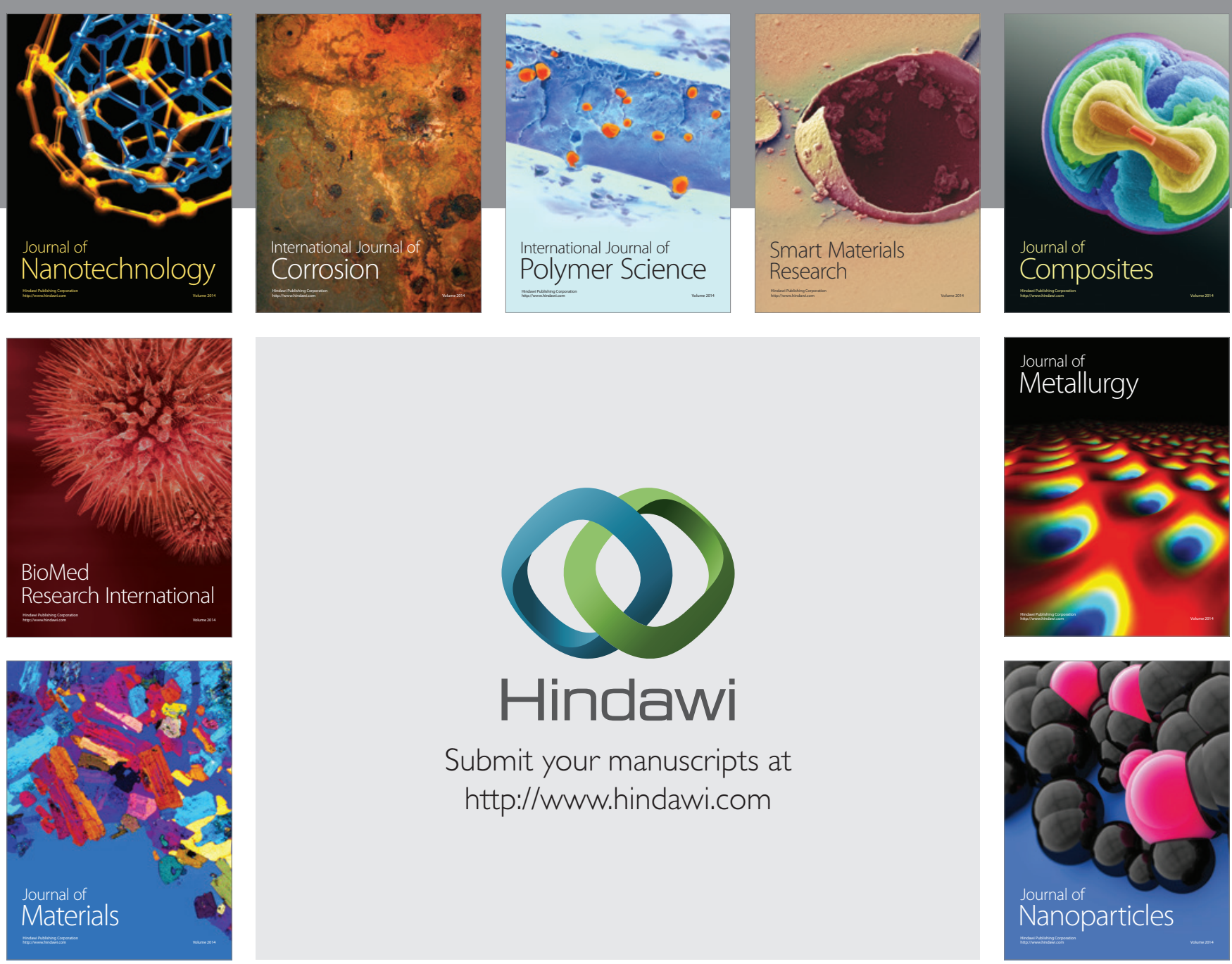

Submit your manuscripts at http://www.hindawi.com
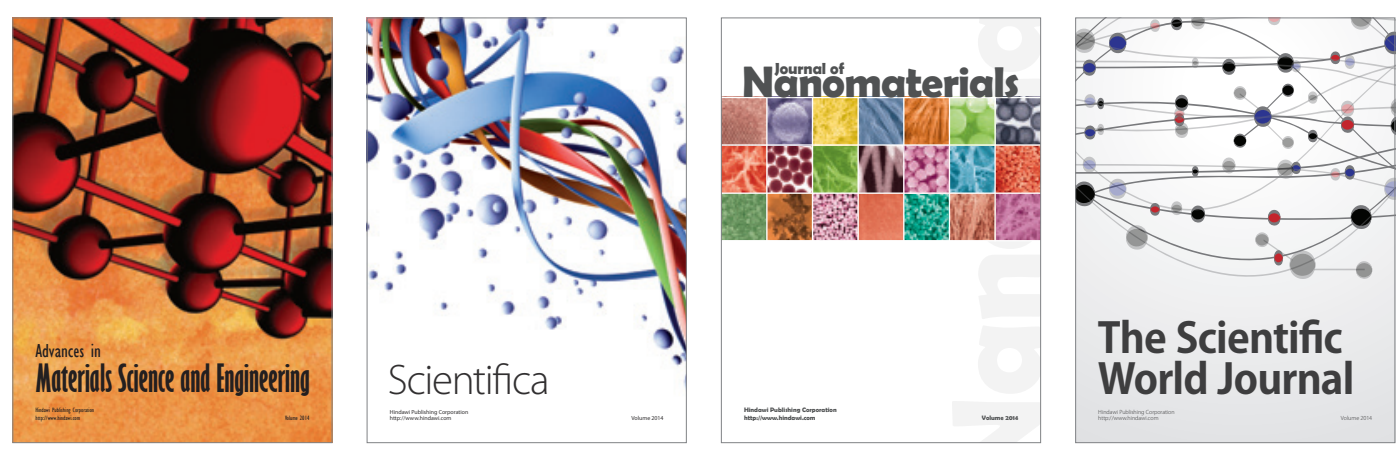

\section{The Scientific World Journal}
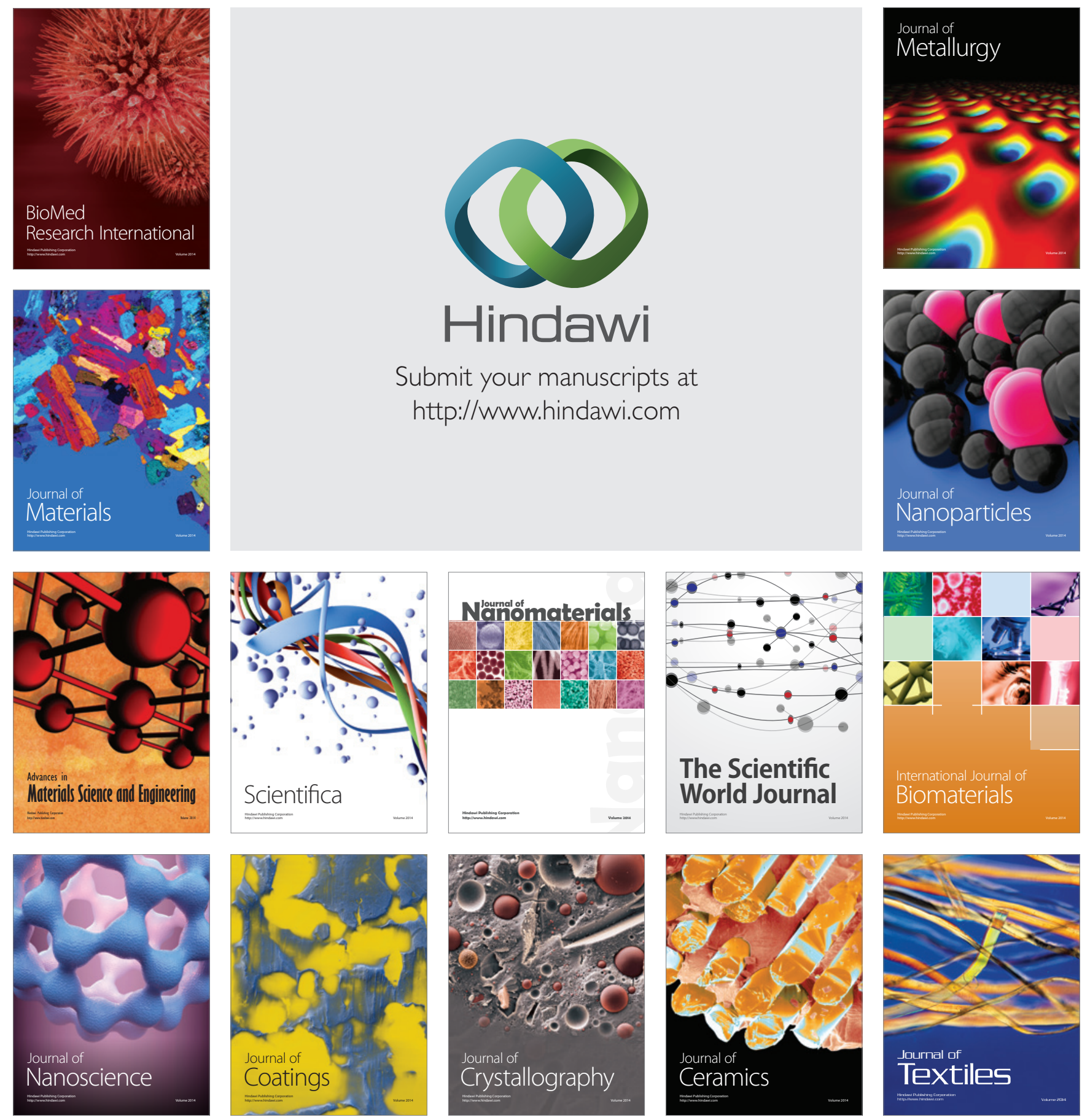